\title{
Cytotoxic Effects of Drug-loaded Hyaluronan-Glutaraldehyde Cross-Linked Nanoparticles and the Release Kinetics Modeling
}

MA Abdullah ${ }^{1 *}$, Gul-e-Saba ${ }^{1}$ and A Abdah ${ }^{2}$

${ }^{1}$ Department of Chemical Engineering, Universiti Teknologi PETRONAS, Bandar Seri Iskandar, 31750, Tronoh, Perak, Malaysia ${ }^{2}$ Department of Biomedical Sciences, Universiti Putra Malaysia, Serdang, 42400, Selangor, Malaysia

\begin{abstract}
In this study, paclitaxel (PTX)-loaded hyaluronic acid (HA) nanoparticles (NPs) were synthesized. FESEM and TEM showed HA-PTX NPs with spherical shape and sizes $>100 \mathrm{~nm}$. TheHA entrapment maintained the crystalline nature of PTX as suggested by XRD, and the entrapment was confirmed by the characteristic peak of PTX at 1736 $\mathrm{cm}^{-1}$ by FTIR. HA-PTX showed cytotoxicity towards lung (A549) $\left(\mathrm{IC}_{50} 0.3 \mu \mathrm{g} / \mathrm{ml}\right)$, breast (MCF-7) $\left(\mathrm{IC}_{50} 0.2 \mu \mathrm{g} / \mathrm{ml}\right)$ and colorectal (HT-29) $\left(\mathrm{IC}_{50} 0.2 \mu \mathrm{g} / \mathrm{ml}\right)$ cancer cells, with 2-3 fold more cytotoxic effects than free PTX. At $10 \mathrm{ng} / \mathrm{ml}$ in A549 cell lines, PTX induced apoptosis, whilst HA-PTX showed enhanced apoptosis. The release kinetics profile showed PTX release in a biphasic manner, with initial burst release of $60-70 \%$, followed by a slow and uniform release. PTX release was best modeled by first-order kinetics, Higuchi and Korsmeyer-Peppas models suggesting that it was concentration dependent, with anomalous, non-Fickian diffusion as a predominant mechanism for the drug transport.
\end{abstract}

Keywords: Hyaluronan; Paclitaxel; Drug delivery; Drug release models; Cytotoxicity; Cisplatin

\section{Introduction}

Cancer continues to become a major killer with about 12.7 million cases and 7.6 million deaths reported. Out of these, $56 \%$ of the cases and $64 \%$ of the deaths occur in the developing world [1]. Compounding the problem are the drug adverse side effects, and the estimated $40 \%$ of the drugs in the pipeline not deliverable through the preferred route or in some cases, at all, owing to poor water solubility [2]. Regular screening and improved patient prognosis could enhance the survival rate. There are now developments in imaging technologies together with advancement in nanotechnology but high equipment costs dampen rapid progress. Chemotherapy has been an important component of cancer clinical management along with radiotherapy, in which the combined effects show more promising results [3-5]. The use of pharmaceutical solvents to increase drug solubility may however have disastrous effects [6].

Effective Drug-delivery systems (DDS) are being developed for targeted delivery to tumor cells and spare the normal tissues, with reduced severe systemic toxicity within the therapeutic concentration [7]. Ligation of anticancer drug to a biocompatible polymer could enhance drug stabilization, localization and controlled release with improved bioavailability of chemotherapeutic agents. Sustainedrelease formulations for many hydrophobic drugs are difficult because they may be released too slowly from the nanoparticles (NPs), thus diminishing the efficacy. Modifying water uptake into the NPs can speed up the release, whilst at the same time retaining the desired drug sustained-release profile [8].

Nano-vehicle aims to reduce adverse side effects with improved bioavailability of chemotherapeutic agents [9], and these include liposomes, polymer therapeutic conjugates, polymeric micelles, dendrimers, nanoshells and nucleic acid-based nanoparticles. The wide applications of polymeric nano-carriers are due to their characteristic features and remarkable results in preclinical studies, demonstrating their potential as therapeutic carriers [10]. Nanomedicines confer several advantages over naked drug such as reducing premature degradation, improving interaction with the biological environment, enhancing absorption or bioavailability into selected tissue and prolonging retention time with effective intracellular penetration [11]. Rapid advances in cell and molecular biology and genomics and proteomics research could further facilitate identification of novel tumor-specific molecular targets and better understanding of the pathophysiology of various diseases, leading to improved diagnosis and ultimately disease therapy [12].

Hyaluronic acid (HA) is a glycosaminoglycan found inside human body and distributed throughout the epithelial, connective, and neural tissues $[13,14]$. It is the main component of the extracellular matrix and the main ligand for CD44 and Receptor for Hyaluronan-Mediated Motility (RHAMM). The receptors are over-expressed in a variety of tumor cell surfaces including human breast epithelial cells, colon cancer, lung cancer and acute leukemia cells. Due to the versatile nature of HA, bio-conjugates of low molecular weight $\mathrm{HA}$ with cytotoxic agents have been developed $[15,16]$. The aim is to improve solubility of cytotoxic agent to facilitate its intravenous administration and for effective targeting to cancerous cells, with enhanced therapeutic efficiency and sustained/control release properties [14].

Paclitaxel (PTX), a diterpenoid originally isolated from the bark of the Pacific yew, Taxusbrevifolia, is a powerful anti-mitotic agent. It binds to microtubules, inhibits their depolymerization into tubulin, and stabilizes tubulin polymerization resulting in cell cycle arrest and mitosis inhibition. Although PTX has shown remarkable potential as anticancer compound, it causes toxicity, with drug resistance in some tumors, and has poor stability and sparing aqueous solubility. Taxol ${ }^{\mathrm{TM}}$, the clinically used formulation of PTX, contains polyoxyethylated

*Corresponding author: MA Abdullah, Department of Chemical Engineering, UniversitiTeknologi PETRONAS, Bandar Seri Iskandar, 31750, Tronoh, Perak, Malaysia, Tel: 605-3687636; Fax: 605-3656176; E-mail: azmuddin@petronas.com.my

Received December 20, 2013; Accepted February 17, 2014; Published February 25, 2014

Citation: Abdullah MA, Gul-e-Saba, Abdah A (2014) Cytotoxic Effects of Drugloaded Hyaluronan-Glutaraldehyde Cross-Linked Nanoparticles and the Release Kinetics Modeling. J Adv Chem Eng 1: 104. doi: 10.4172/2090-4568.1000104

Copyright: (c) 2014 Abdullah MA, et al. This is an open-access article distributed under the terms of the Creative Commons Attribution License, which permits unrestricted use, distribution, and reproduction in any medium, provided the original author and source are credited. 
castor oil (Cremophor ${ }^{\mathrm{TM}}$ EL) and ethanol. Cremophor, is considered responsible for hypersensitivity reactions and the side effects observed with PTX infusions which include nausea, vomiting, diarrhea, mucositis, myelosuppression, cardiotoxicity, and neurotoxicity [14,17]. Cisplatin $(\mathrm{Pt})$ is another widely used chemotherapeutic agent to treat a variety of solid tumors [18]. Its therapeutic effect is dose limiting due to the presence of side effects such as gastrointestinal disturbance and especially nephrotoxicity [19]. Anti-cancer drugs coupled to HA can provide advantages in drug solubilization, stabilization, localization and controlled release [20].

In the current study, PTX-entrapped HA nanoparticles were synthesized and characterized. The cytotoxic effects on breast (MCF-7), lung (A549) and colorectal (HT-29) cancer cell-lines were determined. The morphological and cell analysis were observed under inverted microscopy and flow cytometry. The interpretation of PTX released kinetics and mechanism based on zero order and first order kinetics and the drug release models based on Higuchi, Korsmeyer Peppas and Hixson-Crowell were established.

\section{Materials and Methods}

Human breast (MCF-7), colorectal (HT-29) and lung cancer cell lines (A549) were purchased from American Tissue Culture Collection. The Roswell Park Memorial Institute (RPMI) and Dulbecco's Modified Eagle Media (DMEM) werepurchased from PAA Laboratories (Linz, Austria). Fetal Bovine Serum (FBS), penicillin-streptomycin, TrypsinEDTA and hyaluronic acid sodium salt (MW 1.5 MDa) isolated from Streptococcus equisp were purchased from Sigma Aldrich. Paclitaxel (MW 853.9) was purchased from Acros Organic (USA). Apoptosis and necrosis study was done by using FITC AnnexinV Apoptosis Detection kit USA. All chemicals were of analytical grade.

\section{Synthesis}

The synthesis of HA-PTX NPs was prepared by using desolvation method with polymer cross-linking with a slight modification [20]. High molecular weight HA (1.5 MDa) degradation was achieved in dilute $\mathrm{HCl}(\mathrm{pH} 0.5)$ for $24 \mathrm{~h}$ at $37^{\circ} \mathrm{C}$, and stirred at $180 \mathrm{rpm}$ to produce low molecular weight (LMW) HA $(3.5 \mathrm{kDa})$ [21]. The product was then collected by the dialysis tube of $3.5 \mathrm{kDa}$ MW. HA powder of $100 \mathrm{mg}$ was dissolved in $10 \mathrm{ml}$ of deionized water containing $2 \%$ Tween 20 . The solution was heated at $40^{\circ} \mathrm{C}$ with constant stirring at $500 \mathrm{rpm}$ to ensure homogeneous mixing. Two $\mathrm{ml}$ of $20 \%$ sodium sulfate was added slowly, followed by $1 \mathrm{ml}$ of acetone containing $1 \mathrm{mg}$ of PTX. Then, $9 \mathrm{ml}$ of $20 \%$ sodium sulfate was added until the HA aggregates were formed, noted by changes in solution from clear to turbid. One $\mathrm{ml}$ of water was added, which changed the color from turbid back to clear solution. This was followed by adding $0.5 \mathrm{ml}$ of glutaraldehyde solution (25\%) to cross-link the HA. Four ml of sodium meta-bisulfite solution (12\%) was added after 30 mins to stop the cross-linking process. After $2 \mathrm{~h}$, the crude product was purified by dialysis method using $25 \mathrm{kDa}$ MW tube and then lyophilized in a freeze drier over a $48 \mathrm{~h}$ period.

\section{Characterization}

Field emission scanning electron microscope (FESEM) and transmission electron microscopy (TEM): The morphology of HAPTX NPs was characterized by FESEM (55 VP, Zeiss Supra) and TEM ( $80 \mathrm{kV}$ 200FE Zeiss Libra). HA-PTX NPs was mounted on carbon tape and observed under FESEM. For TEM, one drop of PNPs suspension was placed on a carbon film coated on a copper grid.

Fourier transform infrared spectroscopy (FTIR): IR spectra measurements were performed for a thin HA-PTX NPs pellet using a Shimadzu FTIR-8100 IR spectrometer (Kyoto, Japan) by KBr pellets at 5:95 ratio.

X-ray diffraction (XRD): XRD of HA cross-linked NPs (void) and HA-PTX NPs were obtained with a D8-Advance Bruker (AXS) using $\mathrm{CuK} \alpha$ radiation $(40 \mathrm{kV}, 20 \mathrm{~mA})$ to determine the crystallinity of PTX in cross-linked HA. All experiments were performed at room temperature.

\section{Cell culture}

The MCF-7 and HT-29 cell lines were maintained in RPMI 1640 culture medium; and A549 in DMEM supplemented with 10\% FBS and $1 \%$ antibiotics (100 IU $/ \mathrm{ml}$ penicillin and $100 \mu \mathrm{g} / \mathrm{ml}$ streptomycin). Cell lines were grown in $25 \mathrm{~cm}^{3}$ and $75 \mathrm{~cm}^{3}$ tissue culture flasks in a humidified atmosphere, containing $5 \% \mathrm{CO}_{2}$ and $95 \%$ air, at $37^{\circ} \mathrm{C}$. The changing of media was done every 2-3 days, by replacing old media with fresh media, after washing cells with PBS (pH 7.4). After the cell growth reached $80 \%$ confluency (as observed under inverted microscope). The sub-culturing was done at 1:3 ratio, in case of $25 \mathrm{~cm}^{3}$ culture flask, or 1:1 ratio in case of $75 \mathrm{~cm}^{3}$ culture flask. The old media was removed and the cells washed with PBS three times. The cells were harvested by adding trypsin $(5 \mathrm{ml})$, spread all over the surface of tissue culture flask and placed in an incubator for 7-10 min. After incubation, cells were detached and then rinsed with culture media before the cells pipetted out.

MTT (3-[4,5-dimethylthiazol-2-yl]-2,5-diphenyl tetrazolium bromide) assay: The in vitro cytotoxicity of anticancer drugs ( $\mathrm{Pt}$ and PTX), HA-Pt and HA-PTX NPs on A549, MCF-7 and HT-29 were evaluated using MTT assay [22]. MTT assay is a colorimetric assay in which a yellow tetrazolium salt (MTT) is reduced by a viable cell mitochondrial enzyme (dehydrogenase) to produce purple crystals of formazan. The amount of colored product formed is directly proportional to the number of viable cells. Solution of Pt, PTX, HAPt and HA-PTX NPs was freshly prepared in PBS, dimethyl sulfoxide (DMSO) and media, as described earlier.

Cells were seeded into 96 -well plate $(\sim 5000$ cells/ml $)$ in $100 \mu \mathrm{l}$ of RPMI or DMEM and incubated for $24 \mathrm{~h}$. Different concentrations of Pt and HA-Pt $(0.01,0.1,1,10,100,1000,10000 \mu \mathrm{g} / \mathrm{ml})$ were prepared in culture media. The concentration of PTX and HA-PTX were prepared in culture media at $0.001,0.01,0.1,1,10,100 \mu \mathrm{g} / \mathrm{ml}$. The individual cell lines treated with Pt, HA-Pt, PTX and HA-PTX at various concentrations were incubated at $37^{\circ} \mathrm{C}$ with $5 \% \mathrm{CO}_{2}$ in a humidified atmosphere for 24,48 and $72 \mathrm{~h}$. Cells were treated with $20 \mu \mathrm{l}$ of 3-(4,5-dimethylthiazol2-yl) - 2,5 diphenyltetrazolium bromide (MTT) and incubated for $4 \mathrm{~h}$. Medium was removed and $100 \mu \mathrm{l} \mathrm{DMSO} /$ well was added to dissolve formazan purple crystal. The MTT reading was done at 570 $\mathrm{nm}$, with reference at $630 \mathrm{~nm}$, using UVM 340 micro plate reader. Each experiment was carried out in triplicate in three independent experiments for each cell line.

The percentage of cytotoxicity was calculated as follows [23]:

$$
\text { Cell viability }(\%)=\left(\frac{O D_{\text {sample }}-O D_{\text {blank }}}{O D_{\text {control }}}\right) \times 100 \%
$$

Where $O D_{\text {sample }}$ represents the optical density (absorbance) of the samples (drug at respective concentration + media + cells), $O D_{\text {blank }}$ as the optical density of the blank (drug + media only), and $O D_{\text {control }}$ as the optical density of the control wells without treatments (cells + media only).

A dose-response curve (percentage of cell viability versus sample 
Citation: Abdullah MA, Gul-e-Saba, Abdah A (2014) Cytotoxic Effects of Drug-loaded Hyaluronan-Glutaraldehyde Cross-Linked Nanoparticles and the Release Kinetics Modeling. J Adv Chem Eng 1: 104. doi: 10.4172/2090-4568.1000104

concentration) was plotted and the sample concentration that inhibits $50 \%$ of the cell viability $\left(\mathrm{IC}_{50}\right)$ was determined from the graph. The procedure was repeated for each sample and cell line.

\section{Morphological analysis of apoptosis and necrosis}

Inverted microscopy: Cell morphology was observed under inverted microscope (Motic AE31). The MCF-7, A549 and HT-29 cells were seeded for 24 hours. After washing the cells with PBS, the old media were replaced with fresh media. Cell lines were treated with $10 \mathrm{ng} / \mathrm{ml}$ concentrations of PTX and HA-PTX NPs for $24 \mathrm{~h}$ and the morphological characteristics were observed.

Flow cytometric analysis: FITC Annexin V in combination with propodiumiodidie (PI) staining were used for quantitative determination of cells undergoing apoptosis and necrosis. The A549 cells was grown in $25 \mathrm{~cm}^{3}$ and $75 \mathrm{~cm}^{3}$ culture flasks separately, incubated at $37^{\circ} \mathrm{C}$ in $5 \% \mathrm{CO}_{2}$. Apoptosis and necrosis study was done by using FITC AnnexinV Apoptosis Detection kit US as per manufacturer protocol. Cells were individually treated for 24 hwith $10 \mathrm{ng} / \mathrm{ml}$ of free PTX and HA-PTX NPs, and then stained with annexin V and PI, and analyzed by flow cytometry (BD FACSAria). The untreated stain and unstained cells were used as a control group. The live cells are annexin $\mathrm{V}$ and propidium iodide negative $\left(\mathrm{V}^{-} / \mathrm{PI}^{-}\right)$; the cells undergoing apoptosis are annexin $\mathrm{V}$ positive and propidium iodide negative $\left(\mathrm{V}^{+} /\right.$ $\mathrm{PI}^{-}$); the cells undergoing late apoptosis or necrosis are both annexin $\mathrm{V}$ and propidium iodide positive $\left(\mathrm{V}^{+} / \mathrm{PI}^{+}\right)$; and the dead cells are annexin $\mathrm{V}$ negative and propidium iodide positive $\left(\mathrm{V}^{-} / \mathrm{PI}^{+}\right)$. The apoptotic program is characterized by morphological features including loss of plasma membrane asymmetry, condensation of cytoplasm and nucleus with DNA fragmentation. When apoptosis happened in the cells, the membrane phospholipid phosphatidylserine (PS) translocate from inside to outside. As a result of its translocation, annexin $\mathrm{V}$ which is a flourochrome conjugates and binds to PS due to high binding affinity. However, the dead and necrotic cells are permeable to PI.

\section{PTX encapsulation and release}

Encapsulation efficiency: The amount of entrapped PTX in HAPTX NPs was detected in triplicate by UV/Visible Spectrophotometer. Four mg of HA-PTX NPs were dispersed in $1 \mathrm{ml}$ of Phosphate Buffer Saline (PBS) solution. One $\mathrm{ml}$ of hyaluronidase $(1 \mathrm{mg} / \mathrm{ml}$ in PBS) was used to digest the HA-PTX NPs in a shaker incubator at $37^{\circ} \mathrm{C}$. After about $1.5 \mathrm{~h}$ incubation, extraction was done with ethyl acetate, which was further dried under nitrogen blanket and then reconstituted in 200 $\mu \mathrm{L}$ PBS. The encapsulation efficiency (EE) of PTX in HA-PTX NPs was calculated as follows [23]:

$$
\begin{aligned}
& \mathrm{PTX}_{\mathrm{TOTAL}}=\mathrm{PTX}_{\text {ENTRAPPED }}+\mathrm{PTX}_{\mathrm{FREE}} \\
& \mathrm{EE} \%=\left(\frac{\text { Amount of entrapped PTX in HA-PTX NPs }}{\text { Theoretical amount of PTX used }}\right) \times 100 \%
\end{aligned}
$$

PTX release: To test the release characteristics of the PTX from HA-PTX NPs, dialysis method was used. [23]. Twenty mg of the HAPTX NPs was resuspended in $5 \mathrm{~mL}$ of PBS (pH 7.4) and transferred to a dialysis tube (MWCO of $2 \mathrm{~g} / \mathrm{mol}$ ). The dialysis tube was placed in a $200 \mathrm{~mL}$ bottle with $95 \mathrm{~mL}$ of PBS. PTX release was studied at $100 \mathrm{rpm}$ at $37^{\circ} \mathrm{C}$. Two $\mathrm{ml}$ of the sample solution was taken and the solution was supplemented with $2 \mathrm{ml}$ of fresh PBS after $2 \mathrm{hr}$ intervals. The amount of PTX released was further evaluated by UV spectrophotometry at 310 nm wavelength.

Modeling: To study the release kinetics data of PTX from HA-PTX
NPs, data was fitted into five kinetics and mechanistic models. The rate constants and regression coefficients, $R^{2}$, were determined.

The zero-order kinetics was evaluated as follows:

$C_{o}-C_{t}=K_{o} t$

Rearrangement of equation (3) gives:

$C_{t}=C_{o}+K_{o} t$

Where $C_{t}$ is the amount of drug $\left(\mathrm{mg} \mathrm{L}^{-1}\right)$ dissolved in time $t(\mathrm{hr}), C_{o}$ is the initial amount of drug $\left(\mathrm{mg} \mathrm{L}^{-1}\right)$ in the solution $\left(C_{o}=0\right)$ and $K_{o}$ is the zero order release constant $\left(\mathrm{h}^{-1}\right)$

The first-order kinetics was developed based on Eq. (5):

$d C / d t=-K C$

where $d C / d t$ is the rate of change in concentration with respect to time $\left(\mathrm{mg} \mathrm{L}^{-1} \mathrm{~h}^{-1}\right)$, and $K$ is the first order rate constant $\left(\mathrm{h}^{-1}\right)$. Integrated form of equation (3) can be expressed as:

$$
\log C=\log C_{o}-K_{t} / 2.303
$$

where $C_{o}$ is the initial concentration of drug $\left(\mathrm{mg} \mathrm{L}^{-1}\right)$. The data obtained are plotted as log cumulative percentage of drug remaining versus time to yield a straight line with a slope of $K_{t} / 2.303$.

The Higuchi model is proposed as follows:

$$
J=-D(\partial \varnothing / \partial x)
$$

Where $J$ is diffusion flux $\left(\mathrm{mol} / \mathrm{m}^{2} . \mathrm{s}\right) ; D$ is diffusion coefficient $\left(\mathrm{m}^{2} / \mathrm{s}\right) ; \varnothing$ is concentration $\left(\mathrm{mol} / \mathrm{m}^{3}\right) ; x=$ length $(\mathrm{m})$; and

$$
Q=A \sqrt{D(2 C-C) C t}
$$

where $Q$ is the amount of drug released in time $t(\mathrm{hr})$ per unit area $A$ of matrix $\left(\mathrm{mg} / \mathrm{cm}^{2}\right), C$ is the drug initial concentration $\left(\mathrm{mg} \mathrm{L}^{-1}\right)$ and $D$ is the diffusivity of the drug molecules (diffusion coefficient) in the matrix $\left(\mathrm{cm}^{2} \mathrm{hr}^{-1}\right)$,

$$
Q=K_{H} \times t^{1 / 2}
$$

Where $D$ is the diffusion coefficient of the drug molecule in the solvent, $\delta$ is the porosity of the matrix, $\tau$ is the tortuosity of the matrix and $Q, A, C$ and $t$ have the meaning as assigned above, and $K_{H}$ is Higuchi dissolution constant $\left(\mathrm{h}^{-1 / 2}\right)$.

The Hixson-Crowell model is given as follows:

$$
\sqrt[3]{\mathrm{W}_{o}}-\sqrt[3]{\mathrm{W}_{t}}=K t
$$

The Korsmeyer-Peppas model is described as:

$$
M t / M \infty=K t^{n}
$$

$$
\log M t / M \infty=\log K_{K P}+n \log t
$$

where $M t / M \infty$ is the fraction of drug released at time $t(\mathrm{hr}), K_{K P}$ is the release rate constant unit $\left(\mathrm{h}^{-n}\right)$ and $n$ is the release exponent.

\section{Statistical analysis}

All determinations were expressed as means \pm standard error (SE). All the $I C_{50}$ values of Pt, HA-Pt, PTX and HA-PTX on the breast (MCF7), lung (A549) and colorectal (HT-29) cancer cell lines were analyzed using one-way analysis of variance (ANOVA), Tukey HSD, LSD Test, $p<0.05$ and $p<0.01$ ) (SPSS version 15.0). A probability of $p<0.05$ was considered significant, and $p<0.01$ considered as very significant. 
Citation: Abdullah MA, Gul-e-Saba, Abdah A (2014) Cytotoxic Effects of Drug-loaded Hyaluronan-Glutaraldehyde Cross-Linked Nanoparticles and the Release Kinetics Modeling. J Adv Chem Eng 1: 104. doi: 10.4172/2090-4568.1000104

Page 4 of 9

\section{Results and Discussion}

\section{Synthesis and characterization of PTX-entrapped HA NPs}

HA-PTX NPs were successfully synthesized by desolvation method with glutaryldehyde (GA) crosslinking of HA, which appeared as fine white powder, whilst void HA NPs were coarser. The desolvation method offers the advantage of producing NPs directly in aqueous suspension. It does not require heat treatment and may be useful for biopolymers and heat sensitive drug formulations [18]. Although both ethanol and acetone can be used as desolvating agent in the preparation of NPs [24-26], acetone was used in this study. Ethanol could inhibit GA crosslinking of HA as shown by a study on protein crosslinking by GA where the crosslinking is formed between the two polyol molecules [27]. GA has two aldehyde groups and ethanol produces acetals with aldehydes. There is a high probability of the free hydroxyl groups on HA to be in competition with hydroxyl groups of ethanol for reaction with GA, thus reducing the cross-linked HA [26].

Figure $1 \mathrm{a}$ and $1 \mathrm{~b}$ shows the morphology of freeze dried HA-PTX NPs as observed by FESEM and TEM. HA-PTX was shown to have distinct spherical shape with moderate uniformity with sizes in ranges of $100-250 \mathrm{~nm}$. The nanosizes make the NPs easily move into leaky vessels of tumor tissue to target the tumor cells. Figure 2 shows the IR spectrum of void HA NPs and HA-PTX NPs. Peaks at $3400-3600 \mathrm{~cm}^{-1}$ in both are attributed to $\mathrm{OH}$ and $\mathrm{NH}$ group stretching vibrations and residual moisture content. $\mathrm{CH}_{2}$ peaks show asymmetric and symmetric stretching vibrations at $2870-2955 \mathrm{~cm}^{-1}$ and the peaks between 1990 to $2183 \mathrm{~cm}^{-1}$ are due to $\mathrm{C}-\mathrm{N}$ bonding. The peaks at 1638 and $1639 \mathrm{~cm}^{-1}$ are attributable to $\mathrm{N}-\mathrm{H}$ bending vibrations of secondary amide, usually in the range of 1550 to $1640 \mathrm{~cm}^{-1}$ [28]. The peaks at 844 to $846 \mathrm{~cm}^{-1}$ are due to $\mathrm{C}-\mathrm{H}$ bonding and 507 to $534 \mathrm{~cm}^{-1}$ to $\mathrm{C}-\mathrm{H}$ and $\mathrm{C}-\mathrm{X}$ (halogen) bonding. The characteristic peak of PTX at $1736 \mathrm{~cm}^{-1}$ can be observed in HA-PTX NPs spectra but not in void HA [29]. The band due to $\mathrm{CH}_{2}$ scissoring at $1463 \mathrm{~cm}^{-1}$ and the sharp peak at $996 \mathrm{~cm}^{-1}$ may be due to interactions between PTX and HA cross-linked molecule, which are completely absent in void HA NPs. Figure $3 \mathrm{a}$ and $3 \mathrm{~b}$ shows the X-ray diffractograms of void HA and HA-PTX NPs. The void cross-linked HA showed its own intrinsic crystal peaks butthe increased intensity of sharp peaks in HA-PTX diffractograms suggest the crystalline nature of PTX. XRD diffractograms may show typical and more specific peaks of drug crystal, with relatively fewer peaks for void NPs. Our results correlate well with previous study on HA-PLGA encapsulating doxorubicin [30].

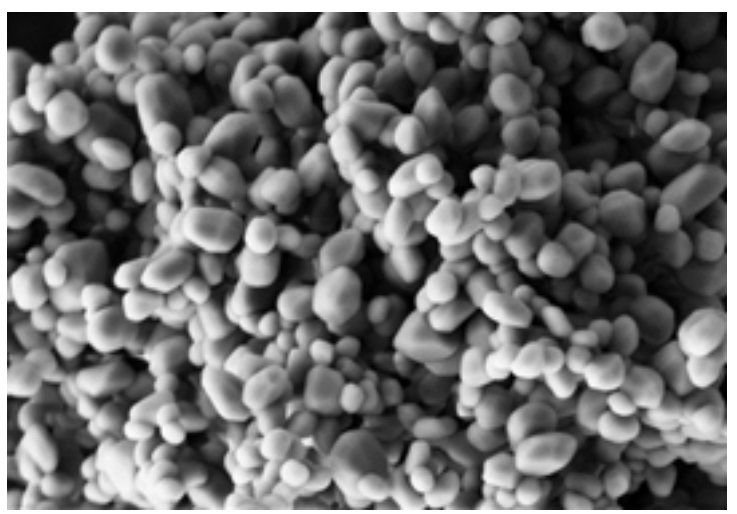

Figure 1a: FESEM image of HA-PTX NPs at $10000^{\times}$magnifications.

\section{Cytotoxicity of drug-loaded NPs}

Figure 4a-4c shows the cytotoxic effects of HA-PTX and PTX on cancer cell lines. The $\mathrm{IC}_{50}$ of HA-PTX NPs after $48 \mathrm{~h}$ for lung (A549) (0.3 $\mu \mathrm{g} / \mathrm{ml} \pm 0.012)$, breast (MCF-7) $(0.2 \mu \mathrm{g} / \mathrm{ml} \pm 0.015)$ and colorectal (HT29) $(0.3 \mu \mathrm{g} / \mathrm{ml} \pm 0.016)$ suggest $2-3$ fold higher cytotoxicity than free PTX. Cytotoxicity of PTX on A549 cells $\left(\mathrm{IC}_{50}=0.7 \mu \mathrm{g} / \mathrm{ml} \pm 0.012\right)$ and the MCF-7 cells $\left(\mathrm{IC}_{50}=0.6 \mu \mathrm{g} / \mathrm{ml} \pm 0.015\right)$ was comparable to previous reports [31,32]. At low PTX $(0.01-0.1 \mu \mathrm{g} / \mathrm{ml})$ after $48 \mathrm{~h}$, significant reduction in cell viability was observed in all the three cell lines, but lower change was observed at higher concentration (1-10 $\mu \mathrm{g} / \mathrm{ml})$. Time dependant changes were observed in A549 and MCF-7, but not so clear in HT-29 cell lines. At $1 \mu \mathrm{g} / \mathrm{ml}$, there were less than $50 \%$ cell viability in A549 and MCF-7, but more than 50\% cell viability was observed in HT-29 cell line.

Table 1 shows the summary of $\mathrm{IC}_{50}$ values of Pt, HA-Pt, PTX and HA-PTX on the three cancer cell lines. PTX was more sensitive towards breast and colorectal cancer cells, while Pt showed dose dependant cytotoxicity in all cancer cell lines. However, the $\mathrm{IC}_{50}$ values of PTX at all times were lower than Pt. The $\mathrm{IC}_{50}$ of $\mathrm{Pt}$ on lung cells in our study corresponds well with the previously reported value $\left(\mathrm{IC}_{50}=2 \mu \mathrm{g} / \mathrm{ml}\right)$, the $\mathrm{IC}_{50}$ of $5 \mu \mathrm{g} / \mathrm{ml} \pm 0.034$ in MCF-7 agrees with previous report $(13 \mu \mathrm{M}=4$ $\mu \mathrm{g} / \mathrm{ml})$; and the $\mathrm{IC}_{50}$ of $8 \mu \mathrm{g} / \mathrm{ml} \pm 0.038$ in HT-29 is close to reported 20 $\mu \mathrm{M}(6 \mu \mathrm{g} / \mathrm{ml})$ [33-35]. The difference in dosage and efficacy could have been a result of mode of action of the drug molecule on specific cancer cells. Pt is a metal based drug for cancer treatment via direct interaction with cell genetic material. The chlorine atom in the Pt molecule is easily

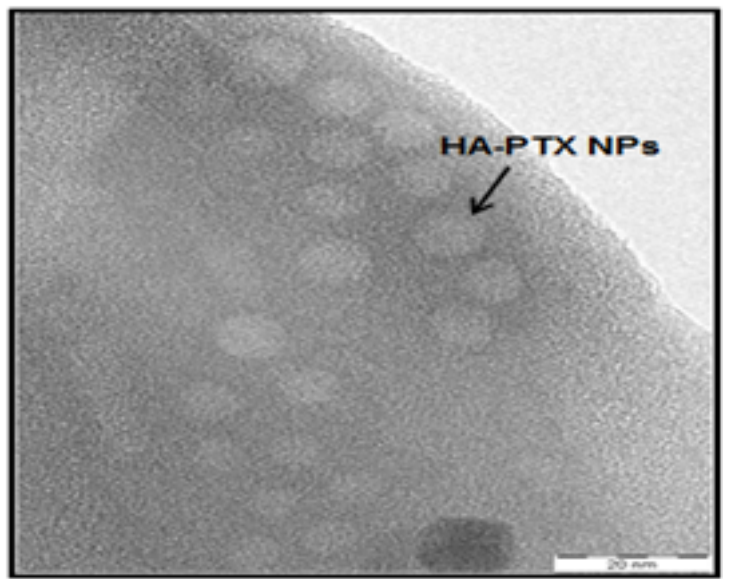

Figure 1b: TEM image of HA-PTX NPs.

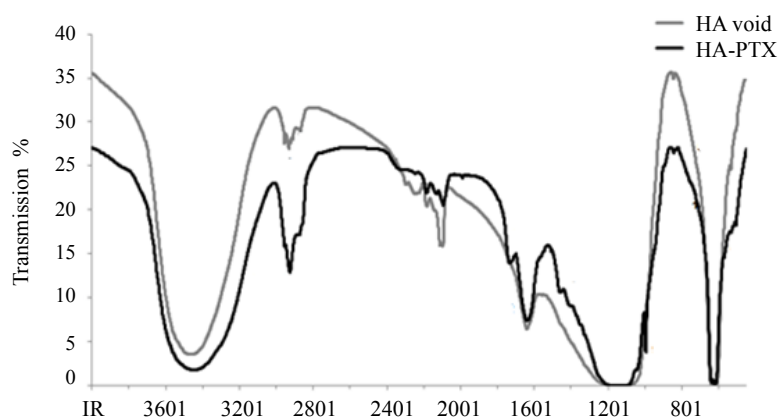

Figure 2: FTIR spectrum of void HA NPs (grey) and HA-PTX NPs (black). 


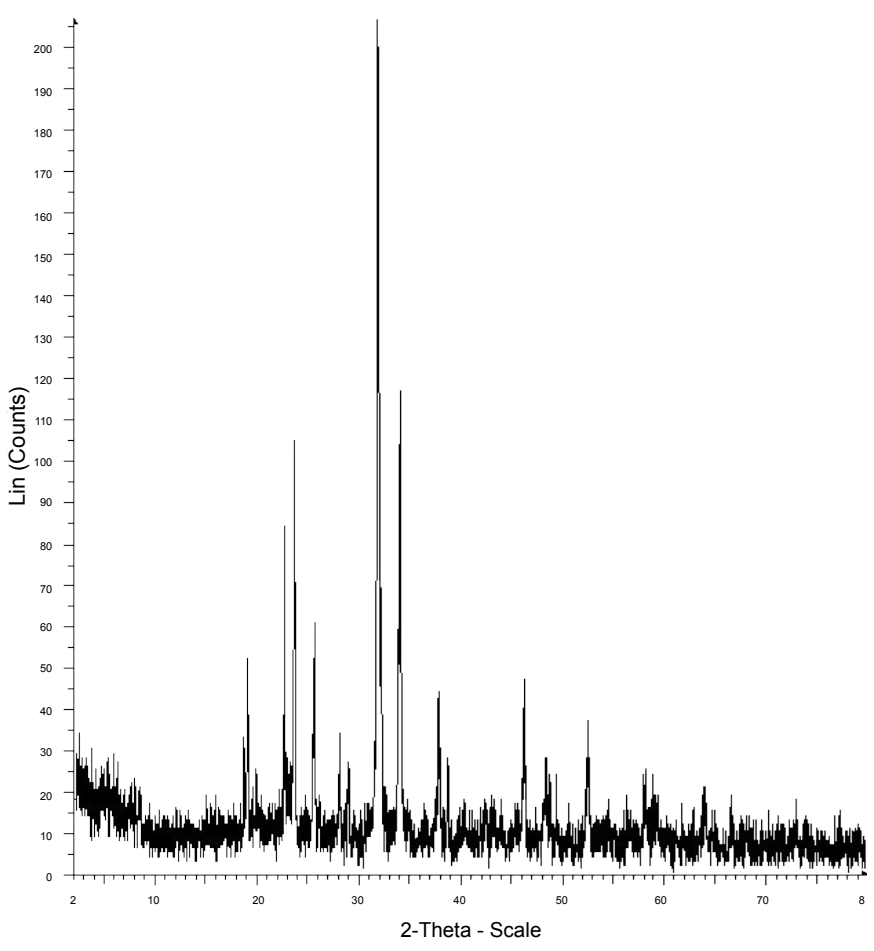

Figure 3a: X-ray diffractogram of void HA NPs.

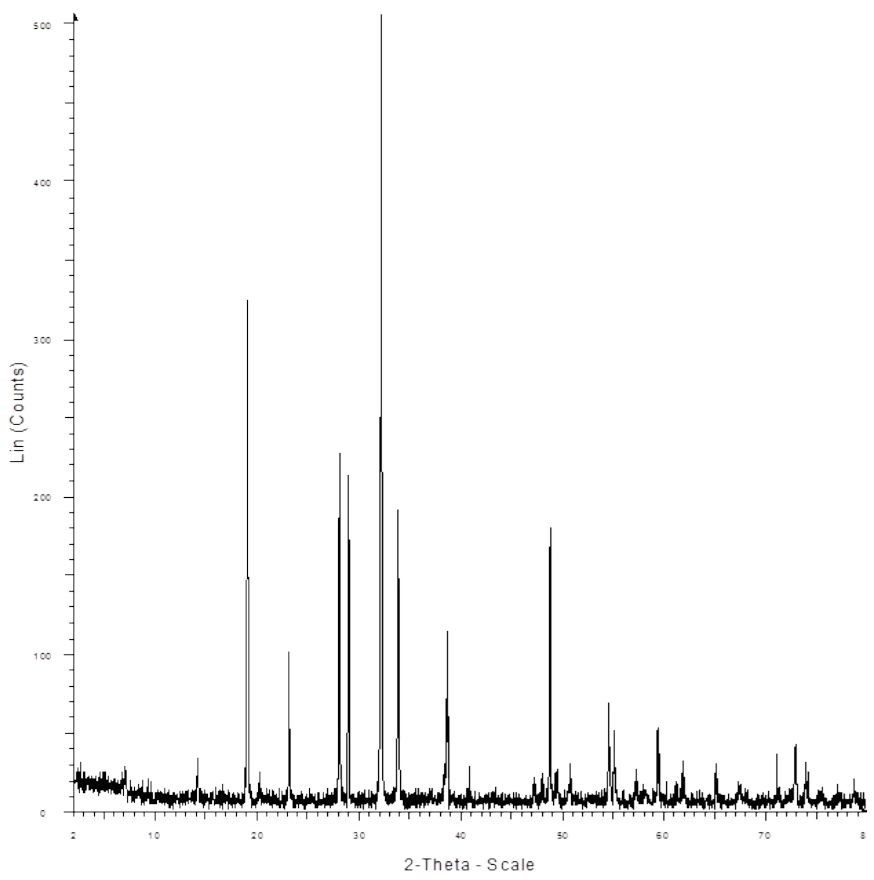

Figure 3b: X-ray diffractogram of HA-PTX NPs.

replaced by a hydroxyl (OH-) group and it binds with a protein on one side and the DNA molecule on the other [36]. Any unstablility in the structure of Pt may result in drug decreased cytotoxicity or drug resistance. The high $\mathrm{IC}_{50}$ values in some cell-lines such as MCF-7 and HT-29 with Pt may suggest drug resistance which may lead to various associated side effects including renal toxicity, nausea and vomiting

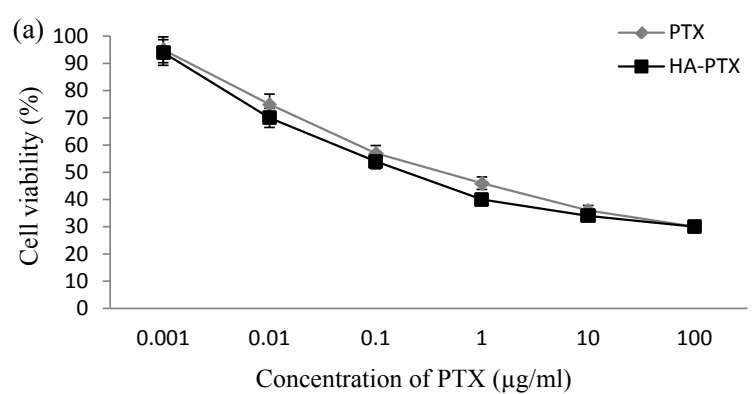

Figure 4a: Cytotoxic effects of PTX and HA-PTX on A549.

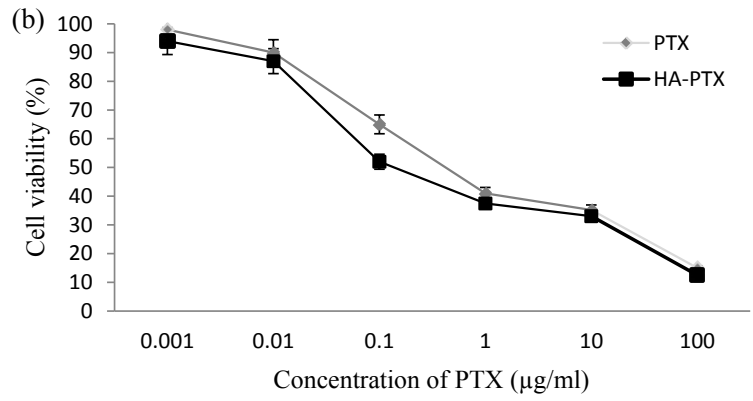

Figure 4b: Cytotoxic effects of PTX and HA-PTX on MCF-7.

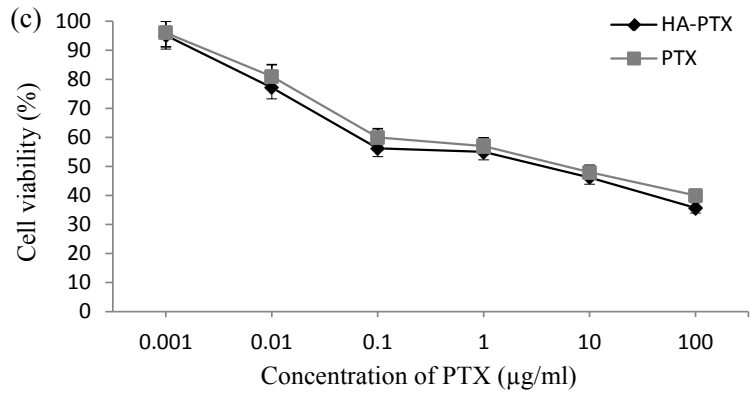

Figure 4c: Cytotoxic effects of PTX and HA-PTX on HT-29 cancer celllines, after $48 \mathrm{~h}$.

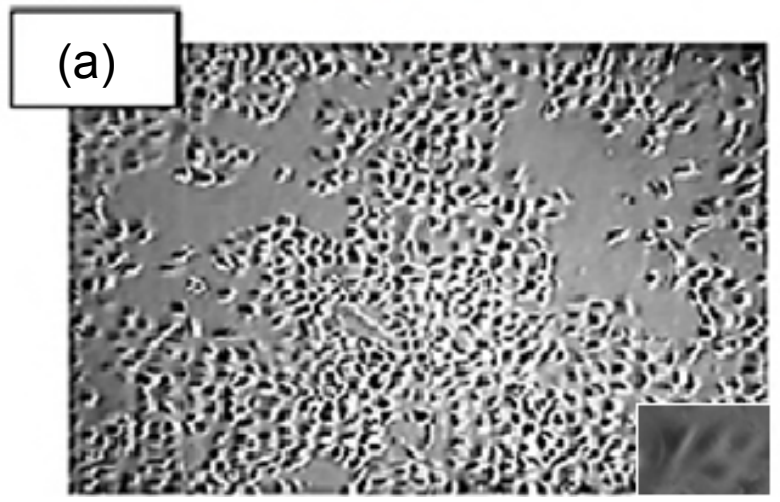

Figure 5a: Morphology of lung cancer cell line (A549) for Control. 
Citation: Abdullah MA, Gul-e-Saba, Abdah A (2014) Cytotoxic Effects of Drug-loaded Hyaluronan-Glutaraldehyde Cross-Linked Nanoparticles and the Release Kinetics Modeling. J Adv Chem Eng 1: 104. doi: 10.4172/2090-4568.1000104

Page 6 of 9

in clinical trials. HA-Pt NPs formed through anionic polymer-metal complexation between Pt and HA, showed not only lower cytotoxicity than HA-PTX, but also no significant difference between Pt and HAPt cytotoxicity in vitro. HA-Pt therefore maintained its cytotoxicity in conjugate form, although HA void NPs did not show any cytotoxic effects up to concentration as high as $10 \mathrm{mg} / \mathrm{ml}$. The non-cytotoxic nature of HA could therefore still possibly reduce the systemic cytotoxicity and enhance the accumulation of cisplatin towards the site of tumor via HA-CD44 receptor-ligand uptake mechanism [7].

\section{Morphological characterization}

The morphological observation of lung (A549) cancer cell lines was studied under light microscope and flow cytometry at $10 \mathrm{ng} / \mathrm{ml}$ of HAPTX NPs and PTX treatment for 24 hours (Figures 5 and 6). Two major cell characteristics of cell death were evaluated - apoptotic cell death which is a physiological or programmed cell death, and necrotic cell death which is an accidental cell death.The control (untreated) cells were larger, rounded and appeared to be healthy with no apoptotics bodies or necrotic cells. After $24 \mathrm{~h}$, cells exhibited condensation with apoptotic bodies (shown by the arrow), which were more profound with HA-PTX treatment than free PTX. The cells were round or oval in shape, smaller in size than the cell of origin. A549 cells showed characteristic changes of apoptotic cell death with nucleus becoming phase-dense, due to condensation of nuclear chromatin, and membrane blebbing, resulting in condensed rounded cells, and fragmentation, which resemble previous studies [37,38]. Flow cytometric analysis (Figure 6) suggests thatapoptosis $\left(\mathrm{V}^{+} / \mathrm{PI}^{-}\right)$was higher after treatment with HA-PTX NPs as compared to free PTX, but high $\mathrm{PI}^{+}$(necrosis) was observed after treatment with PTX as compared to HA-PTX NPs. The PTX-induced apoptosis correlate well with previous studies $[39,40]$ and this may be triggered through different mechanisms depending on cell cycle stage. PTX induces necrosis by disrupting the plasma membrane integrity of mitotic cells, where the treated cells release significant amount of Lactate dehydrogenase (LDH) and some growth-inhibitory substances into the supernatant [39]. The annexin $\mathrm{V}^{-} / \mathrm{PI}^{+}$double staining assay reveals early necrotic cells among the mitotic cells. Low concentration of PTX may cause apoptosis without the appearance of mitotic arrest. PTX is a powerful antimitotic agent which promotes stabilization of tubulin polymerization and consequently cell cycle arrest at the G2/M phase, resulting in inhibition of mitosis and apoptotic cell death. PTX binds selectively and reversibly to the $\beta$ subunit of tubulin, to promote tubulin polymerization and formation of stable microtubules even in the absence of GTP. This leads to disruption of the equilibrium between the tubulin dimer-polymer in favour of polymer assembly [41].

\section{PTX release kinetics and modeling}

The PTX entrapment efficiency as calculated by equations (2) and (3) was $84 \%$ which was similar to the reported PTX-loaded chitosan microspheres at $84 \%$ [29], but higher than HA-Pt conjugation of $73 \%$ [42], and HA-Pt NPs of 81\% [43]. To assess the potential of HA NPs as a control drug carrier of PTX, the release behaviour of 1\% PTX from HA NPs was assessed at $37^{\circ} \mathrm{C} \pm 1$ in PBS ( $\mathrm{pH}$ 7.4) using dialysis method. As shown in Figure 7, the PTX release from the NPs involves two phasesan initial burst phase for the first $12 \mathrm{~h}$, with about $60-70 \%$ drug release, followed by a continuous release phase until $48 \mathrm{hrs}$. Initial phase could be due to those PTX located on or near the surface of NPs; while the second slow and uniform release could be caused by the drugs from inside the NPs. The release kinetics may follow 3 stages: (i) penetration

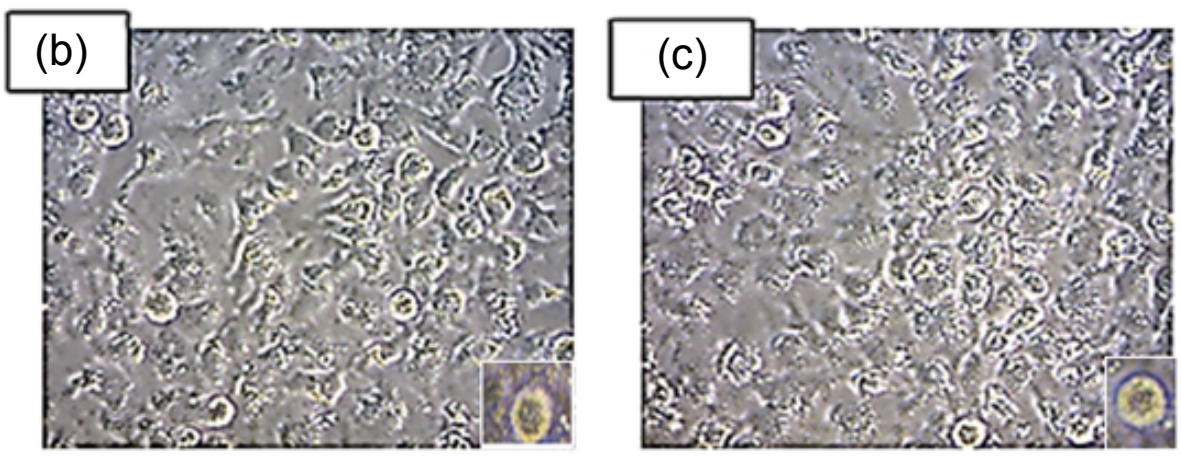

Figure 5b and c: Morphology of lung cancer cell line (A549) for PTX treated HA-PTX treated at $10 \mathrm{ng} / \mathrm{ml}$ after $24 \mathrm{~h}$.

(a)

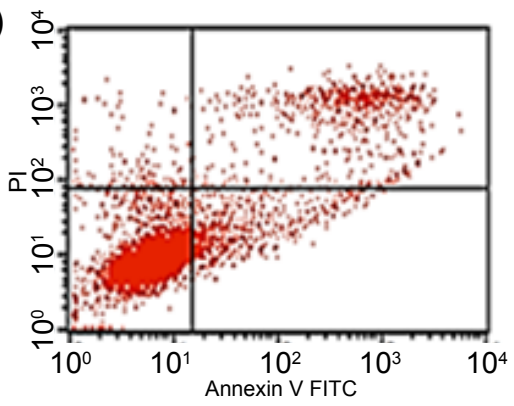

(b)

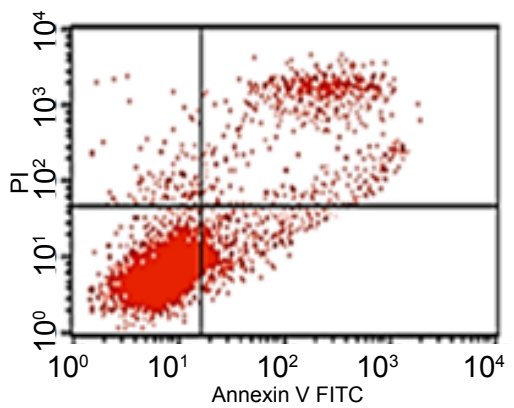

Figure 6: Flow cytometric analysis of lung cancer cell line (A549) for a) PTX-treated and b) HA-PTX treated at $10 \mathrm{ng} / \mathrm{ml}$ after $24 \mathrm{~h}$. 
Citation: Abdullah MA, Gul-e-Saba, Abdah A (2014) Cytotoxic Effects of Drug-loaded Hyaluronan-Glutaraldehyde Cross-Linked Nanoparticles and the Release Kinetics Modeling. J Adv Chem Eng 1: 104. doi: 10.4172/2090-4568.1000104

of the dissolution medium into NPs; (ii) swelling of hydrophilic polymer resulting in the dissolution or erosion of the matrix; and (iii) release of the drug to the surrounding dissolution medium [44]. In our study, the GA cross-linking may have provided controlled release, instead of complete release, as the dissolution of HA may have been slower. Apart from the material construct, the chemical characteristics of drug and drug dosage also affect the release kinetics. The target site in the body and the possible use of $\mathrm{pH}$ or temperature to trigger the drug release are all important considerations to be optimized.

Kinetics study of drug release in vitro will be useful to explain the release behavior of drug from NPs. As diffusion and dissolution are two meaningful influencing factors, the release kinetics can be correlated to bioavailability. Zero order kinetics suggests that the release rate is independent of the concentration of dissolved drug, while first order kinetics describes a concentration-dependant release of drug. As shown in Table 2, with zero-order release kinetic constant for initial burst, $K_{o}=5.726\left(\mathrm{R}^{2}=0.985\right)$ and the overall release $K_{o}=1.719\left(\mathrm{R}^{2}=0.661\right)$, PTX release may be independent of concentration during early release. The overall release however cannot be fully explained by zero-order kinetics. This is different from repaglinide released from PNPs, which shows zero-order release constant, $K_{o}=0.885\left(\mathrm{R}^{2}=0.968\right)$, and ibuprofen release from hydroxypropyl methylcellulose which exhibits zero order constant value $K_{o}=4.004\left(\mathrm{R}^{2}=0.967\right)$, suggesting that both drugs are released independently of drug concentration $[45,46]$. The PTX released from HA-PTX NPs is better described by First-order kinetics as shown in Figure $8 \mathrm{a}$ and $8 \mathrm{~b}$ with the release kinetics of initial burst, $K=0.107\left(\mathrm{R}^{2}=0.999\right)$, and the overall release, $K=0.127\left(\mathrm{R}^{2}=0.963\right)$. The overall PTX release is therefore concentration dependant, and the initial release kinetics corresponds well with ibuprofen release from hydroxypropyl methylcellulose with $K=0.1414\left(\mathrm{R}^{2}=0.993\right)$.

Higuchi model describes the release of drug from matrix as a square root of time dependant process based on Fickian diffusion. HixsonCrowell model proposes drug release from a system where there is a change in surface area and diameter of particles or tablets. The diffusion mechanism is incorporated in Korsmeyer-Peppas model where $K_{K P}$ is the kinetic constant and slope $n$ is an exponent characterizing the diffusional mechanism. The value of $n=0.45$ suggests a Fickian release (case I); between $0.45<\mathrm{n}<0.89$ for non-Fickian diffusion anomalous release; and $=0.89$ for case II (zero order) release. Case II transport generally refers to the dissolution of the polymeric matrix due to the relaxation of the polymer chain, and the anomalous transport (nonFickian) refers to the summation of both diffusion and dissolution of a controlled drug release [44].

The overall release of drug is best explained by Higuchi $\left(R^{2}=0.998\right)$

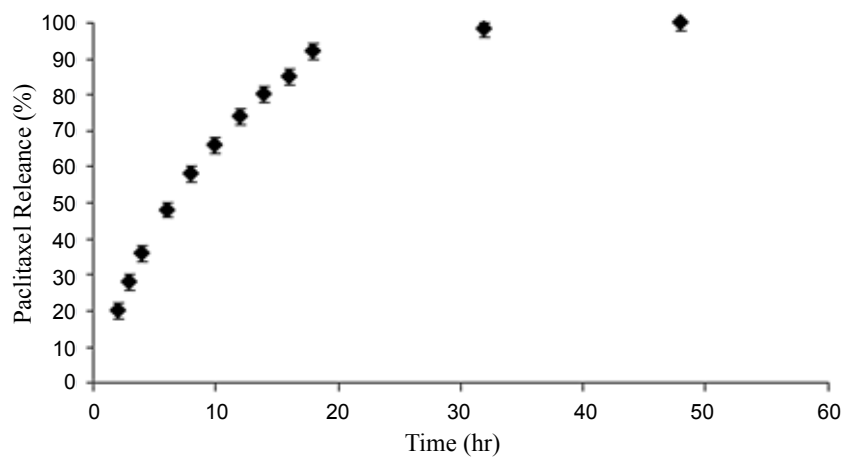

Figure 7: Release kinetics of $1 \%(w / w)$ PTX from HA NPs. and Korsmeyer-Peppas $\left(\mathrm{R}^{2}=0.996\right)$ models as shown in Figures $8 \mathrm{c}$ and $8 \mathrm{~d}$. The released data fitted to Higuchi's Model with $K_{H}=24.87\left(\mathrm{R}^{2}=\right.$ 0.998) agrees well with the release of ibuprofen from hydroxypropyl methylcellulose with $K_{H}=17.569\left(\mathrm{R}^{2}=0.999\right)$ and aceclofenac from hydroxypropyl methylcellulose with $K_{H}=21.73\left(\mathrm{R}^{2}=0.99\right)[46,47]$. The first initial drug release mechanism fitted to Korsmeyer-Peppas model with $K_{K P}=12.336$ and $n=0.7439$ indicates that the non-Fickian diffusion is predominant having anomalous transport including both diffusion and dissolution of controlled drug release. Previous studies with repaglinide have reported $n=0.485$ suggesting that the release rate is diffusion and erosion control mechanism, but with lower $\mathrm{R}^{2}=$ 0.969 [45]. The reported value of $n=0.2465$ is not considered within the limit of Korsmeyer-Peppas model due to complex phenomena (swelling, diffusion and erosion) even with high $\mathrm{R}^{2}=0.994$, but diffusion with erosion could be the mechanism for the drug release from methylocellulose based matrix tablet [46]. Based on Hixson-Crowell model (data not shown), the $K_{H C}=-0.1076\left(\mathrm{R}^{2}=0.956\right)$ was better fitted than the aceclofenac released from Hydroxypropyl methylcellulose with $K_{H C}=-0.134\left(\mathrm{R}^{2}=0.61\right)$ [47]. The low $\mathrm{IC}_{50}$ of HA-PTX as discussed earlier clearly supports the suggestion on successful controlled-release, concentration dependent, diffusion mechanism as proposed by first order kinetics, Higuchi and Korsmeyer-Peppas models.

\section{Conclusion}

PTX entrapped HA NPs were successfully synthesized and developed. The cross-linked HA polymers with entrapped PTX was confirmed by FTIR analysis with the PTX characteristic peaks observed

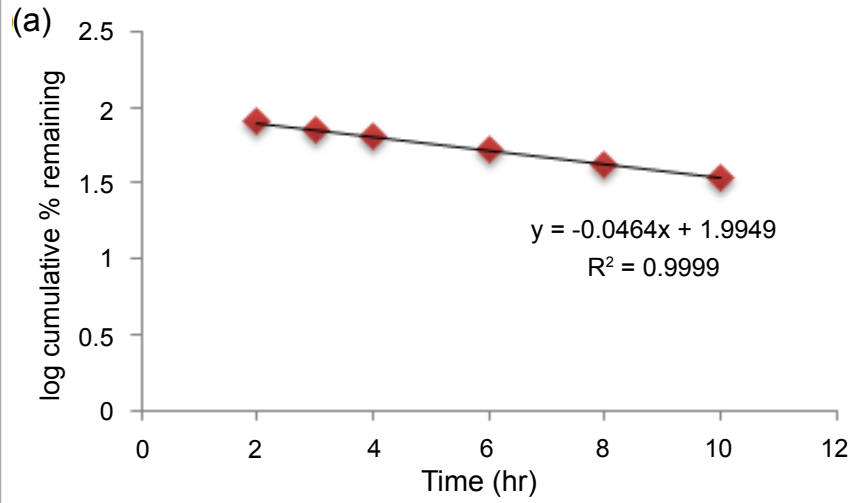

Figure 8a: Release kinetics modeling of PTX from HA NPs based on first order kinetics for $60-70 \%$.

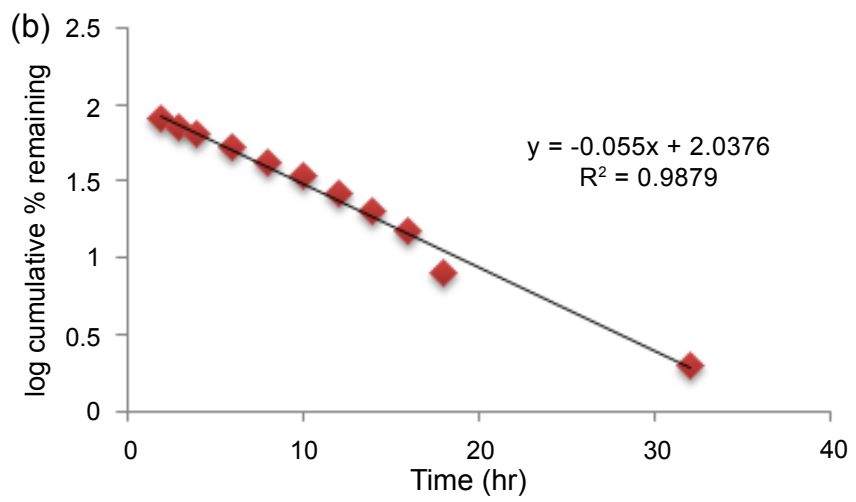

Figure 8b: Release kinetics modeling of PTX from HA NPs based on first order kinetics for $100 \%$. 
Citation: Abdullah MA, Gul-e-Saba, Abdah A (2014) Cytotoxic Effects of Drug-loaded Hyaluronan-Glutaraldehyde Cross-Linked Nanoparticles and the Release Kinetics Modeling. J Adv Chem Eng 1: 104. doi: 10.4172/2090-4568.1000104

(c)

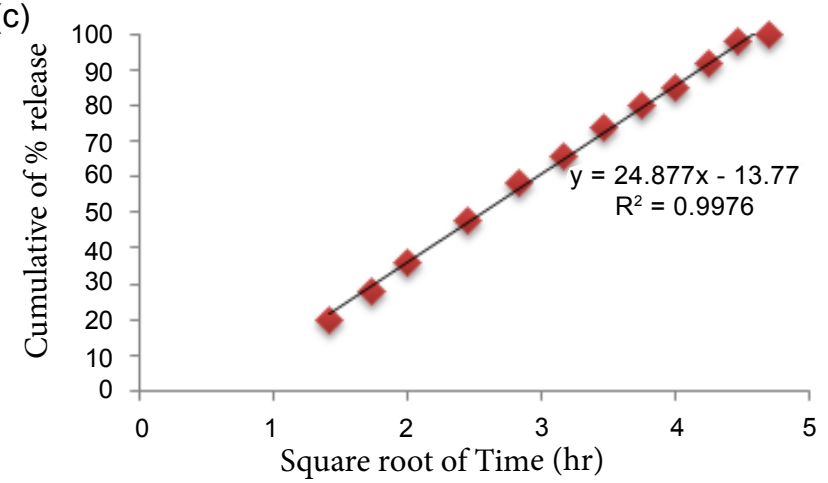

Figure 8c: Release kinetics modeling of PTX from HA NPs based on first order kinetics for Higuchi Model.

(d)

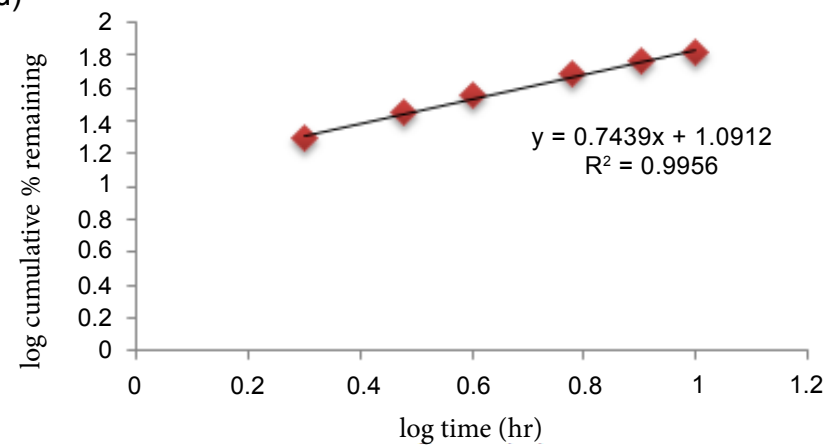

Figure 8d: Release kinetics modeling of PTX from HA NPs based on first orde kinetics for Korsmeyer-Peppas Models.

at $1736 \mathrm{~cm}^{-1}$. HA polymer maintained the crystalline nature of PTX molecules as suggested by XRD. PTX and HA-PTX were more sensitive than cisplatin especially towards breast and lung colorectal cancer cells with HA-PTX showing 2-3 fold more cytotoxic effects than PTX, while HA-Pt had similar cytotoxic effects with cisplatin. PTX induced the morphological changes in A549 cell lines whereFlow Cytometric Analysis showed that PTX induced apoptosis, whilst HA-PTX enhanced the cytotoxicity with increased apoptosis. PTX was released from the HA-PTX NPs in a biphasic manner, where initial drug release data was best fitted to First-order kinetics model, suggesting that the drug release is concentration dependant. The overall PTX drug release kinetics was best described by Higuchi and Korsmeyer-Peppas models where diffusion and dissolution are predominant mechanisms with $n$ value of 0.7439 indicating that the drug transport follows anomalous or non- Fickian diffusion.

\section{Acknowledgments}

This work was partly supported by Biomedical Technology MOR, under Bioengineering Research group, and URIF 12/2011 grant in Universiti Teknologi PETRONAS. Scholarship to Gul-e-Saba is acknowledged.

\section{References}

1. Jemal A, Bray F, Center MM, Ferlay J, Ward E, et al. (2011) Global cancer statistics. CA-Cancer J Clin 61: 69-90.

2. Patel VR, Agrawal YK (2011) Nanosuspension: An approach to enhance solubility of drugs. J Adv Pharm Technol Res 2: 81-87.

3. Gao X, Cui Y, Levenson RM, Chung LWK, Nie S (2004) In vivo cancer targeting and imaging with semiconductor quantum dots. Nature Biotechnol 22: 1-8.
4. Weissleder R (2002) Scaling down Imaging: Molecular Mapping of Cancer in Mice. Nat Rev Cancer 2: 1-8.

5. Wang X, Wang Y, Chen ZG, Shin DM (2009) Advances of cancer therapy by nanotechnology. Cancer Res Treat 41: 1-11.

6. Torchilin VP (2004) Targeted polymeric micelles for delivery of poorly soluble drugs. Cell Mol Life Sci 61: 2549-2559.

7. Vlerken LEV, Amiji MM (2006) Multi-functional polymeric nanoparticles for tumour-targeted drug delivery. Expert Opin Drug Deliv 3: 205-216.

8. Marinich JA, Ferrero C, Jiménez-Castellanos MR (2012) Graft copolymers of ethyl methacrylate on waxy maize starch derivatives as novel excipients for matrix tablets: Drug release and fronts movement kinetics. Eur J Pharm Biopharm 80: 674-681.

9. Farokhzad OC, Langer R (2009) Impact of nanotechnology on drug delivery ACS Nano 3: 16-20.

10. Parveen S, Sahoo SK (2006) Nanomedicine: clinical applications of polyethylene glycol conjugated proteins and drugs. Clin Pharmacokinet 45 965-988.

11. Alexis F, Pridgen E, Molnar LK, Farokhzad OC (2008) Factors affecting the clearance and biodistribution of polymeric nanoparticles. Mol Pharm 5: 505515.

12. Vasir JK, Reddy MK, Labhasetwar VD (2005) Nanosystems in Drug Targeting: Opportunities and Challenges. Curr Nanosci 1: 47-64.

13. Abdullah MA (2010) Hyaluronan-mediated CD44 Receptor Cancer Cells Progression and the Application of Controlled Drug-delivery System. Int J Curr Chem 1: 245-265.

14. Jin YJ, Ubonvan T, Kim DD (2010) Hyaluronic Acid in Drug Delivery Systems J Pharm Investig 40: 33-43.

15. Akima K, Ito H, Iwata Y, Matsuo K, Watari N, et al. (1996) Evaluation of antitumor activities of hyaluronate binding antitumor drugs: synthesis, characterization and antitumor activity. J Drug Target 4: 1-8.

16. Jaracz S, Chen J, Kuznetsova LV, Ojima I (2005) Recent advances in tumortargeting anticancer drug conjugates. Bioorg Med Chem 13: 5043-5054.

17. Jain KK (2008) Drug Delivery Systems: Methods in Molecular Biology, Springer.

18. Yao X, Panichpisal K, Kurtzman N, Nugent K (2007) Cisplatin nephrotoxicity: a review. Am J Med Sci 334: 115-124.

19. Maeda H, Seymour L, Miyamoto $Y$ (1992) Conjugates of anticancer agents and polymers: advantages of macromolecular therapeutics in vivo. Bioconjug Chem 3: 351-362.

20. Al-Ghananeem AM, Malkawi AH, Muammer YM, Balko JM, Black EP, et al. (2009) Intratumoral Delivery of Paclitaxel in Solid Tumor from Biodegradable Hyaluronan Nanoparticle Formulations. AAPS Pharm Sci Tech 10: 407-410.

21. Jeong, Kim ST, Jin SG, Ryu HH, Jin YH, et al. (2008) Cisplatin-Incorporated Hyaluronic Acid Nanoparticles Based on lon-Complex Formation. J Pharm Sci 97: 1268-1276

22. Mossman T (1983) Rapid colorimetric assay for cellular growth and survivals: Application to proliferation and cytotoxicity assays. J Immunol Meth 65: 55-63.

23. Cai S, Xie Y, Bagby T, Cohen MS, Forrest ML (2008) Intralymphatic chemotherapy using a hyaluronan cisplatin conjugate. J Surg Res 147: 247-252.

24. Wang $\mathrm{Y}$, Chen $\mathrm{H}, \mathrm{Ye} \mathrm{C}, \mathrm{Hu}$ Y (2008) Synthesis and characterization of CdTe quantum dots embedded gelatin nanoparticles via a two-step desolvation method. Mat Lett 62: 3382-3384.

25. Tomihata K, Ikada Y (1997) Crosslinking of Hyaluronic Acid with Glutaraldehyde. J Polym Sci A Polym Chem 35: 3553-3559.

26. Jayakrishnan A, Jameela SR (1996) Glutaraldehyde as a fixative in bioprostheses and drug delivery matrices. Biomaterials 17: 471-484.

27. Wong SS (1991) Chemistry of Protein Conjugation and Cross-Linking. CRC Press.

28. Kemp W (1996) Infrared spectroscopy, in Organic Spectroscopy. Macmillan Press, London.

29. Dhanikula AB, Panchagnula R (2004) Development and Characterization of Biodegradable Chitosan Films for Local Delivery of Paclitaxel. AAPS J 6: 27. 
Citation: Abdullah MA, Gul-e-Saba, Abdah A (2014) Cytotoxic Effects of Drug-loaded Hyaluronan-Glutaraldehyde Cross-Linked Nanoparticles and the Release Kinetics Modeling. J Adv Chem Eng 1: 104. doi: 10.4172/2090-4568.1000104

30. Yadav AK, Mishra P, Mishra AK, Mishra P, Jain S, et al. (2007) Development and characterization of hyaluronic acid-anchored PLGA nanoparticulate carriers of doxorubicin. Nanomedicine 3: 246-257.

31. Liu Y, Sun J, Cao W, Yang J, Lian H, et al. (2011) Dual targeting folateconjugated hyaluronic acid polymeric micelles for paclitaxel delivery. Int $J$ Pharm 421: 160-169.

32. Caliceti P, Salmaso S, Bersani S (2010) Polysaccharide-based anticance prodrugs macromolecule anticancer therapeutics. Cancer Drug Discov Dev 2 163-219.

33. St-Germain C, Niknejad N, Ma L, Garbuio K, Hai T (2010) Cisplatin induces Cytotoxicity through the Mitogen-Activated Protein Kinase Pathways and Activating Transcription Factor 3. Neoplasia 12: 527-538.

34. Dhara S, Lipparda SJ (2009) Mitaplatin, a potent fusion of cisplatin and the orphan drug dichloroacetate. Proc Natl Acad Sci 106: 1-6.

35. Serova M, Calvo F, Lokiec F, Koeppel F, Poindessous V (2006) Characterizations of irofulven cytotoxicity in combination with cisplatin and oxaliplatin in human colon, breast, and ovarian cancer cells. Cancer Chemother Pharmacol 57: 491499.

36. Gul-e-Saba, Nasarudin L. Adulphakdee A, Madthing A, Abdullah MA (2012) Hyaluronic acid mediated targeted drug delivery system: A Review. Conference Proceeding: International Conference of Process Engineering and Advance Materials.

37. Huisman C, Ferreira CG, Broker LE, Rodriguez JA, Smit EF (2002) Paclitaxe triggers cell death primarily via caspasein dependent routes in the non-small cell lung cancer cell line NCl-H460. Clin Cancer Res 8: 596-606.

38. Zhou J, Gupta K, Yao J, Ye K, Panda D, et al. (2002) Paclitaxel-resistant human ovarian cancer cells undergo c-Jun NH2-terminal kinase mediated apoptosis in response to noscapine. J Biol Chem 77: 39777-39785.
39. Mailloux A, Grenet K, Bruneel A, Beneteau-Burnat B, Vaubourdolle M, et al. (2001) Anticancer drugs induce necrosis of human endothelial cells involving both oncosis and apoptosis. Eur J Cell Biol 80: 442-449.

40. Giannakakou P, Robey R, Fojo T, Blagosklonny MV (2001) Low concentrations of paclitaxel induce cell type-dependent p53, p21 and G1/G2 arrest instead of mitotic arrest molecular determinants of paclitaxel-induced cytotoxicity. Oncogene 20: 3806-3813.

41. Downing KH (2000) Structural basis for the interaction of tubulin with proteins and drugs that affect microtubule dynamics. Annu Rev Cell Dev Biol 16: 89-111.

42. Cafaggi S, Bignardi G (2008) Cisplatin delivery: a study on a cisplatinhyaluronate complex and nanoparticles formed by its interaction with n-trimethyl chitosan. 6th World Meeting on Pharmaceutics, Biopharmaceutics and Pharmaceutical Technology.

43. Weber C, Kreuter J, Langer K (2000) Desolvation process and surface characteristics of HSA-nanoparticles. Int J Pharm 196: 197-200.

44. Higuchi T (1963) Mechanism of sustained action medication. Theoretical analysis of rate of release of solid drugs dispersed in solid matrices. J Pharm Sci 52: 1145-1149.

45. Lekshmi UMD, Poovi G, Reddy PN (2012) Invitro observation of repanglinide engineered polymeric nanoparticles. DJNB 7: 1-18.

46. Shoib MH, Tazeen J, Merchant HA, Yousuf RI (2006) Evalution of drug release kinectics from ibuprofen matrix tablets using HPMC. Pak J Pharm Sci 19: 119124

47. Poovi G, Dhanalekshmi UM, Narayanan N, Reddy PN (2011) Preparation and characterization of repaglinide loaded chitosan polymeric nanoparticles. Res Nanosci Nanotechnol 1: 12-24. 